\title{
Inhibition-based first-generation electrochemical biosensors: theoretical aspects and application to 2,4-dichlorophenoxy acetic acid detection
}

\author{
Paolo Bollella ${ }^{1}$ - Giovanni Fusco ${ }^{1,2}$ - Cristina Tortolini ${ }^{1,2}$ - Gabriella Sanzò ${ }^{1}$. \\ Riccarda Antiochia $^{1}$ - Gabriele Favero ${ }^{1}$ - Franco Mazzei $^{1}$
}

Received: 5 October 2015 / Revised: 19 January 2016 / Accepted: 2 February 2016

(C) Springer-Verlag Berlin Heidelberg 2016

\begin{abstract}
In this work, several theoretical aspects involved in the first-generation inhibition-based electrochemical biosensor measurements have been discussed. In particular, we have developed a theoretical-methodological approach for the characterization of the kinetic interaction between alkaline phosphatase (AIP) and 2,4-dichlorophenoxy acetic acid (2,4-D) as representative inhibitor studied by means of cyclic voltammetry and amperometry. Based on these findings, a biosensor for the fast, simple, and inexpensive determination of 2,4-D has been developed. The enzyme has been immobilized on screen-printed electrodes (SPEs). To optimize the biosensor performances, several carbon-based SPEs, namely graphite (G), graphene (GP), and multiwalled carbon nanotubes (MWCNTs), have been evaluated. AlP was immobilized on the electrode surface by means of polyvinyl alcohol with styryl-pyridinium groups (PVA-SbQ) as cross-linking agent. In the presence of ascorbate 2-phosphate (A2P) as substrate, the herbicide has been determined, thanks to its inhibition activity towards the enzyme catalyzing the oxidation of A2P to ascorbic acid (AA). Under optimum experimental conditions, the best performance in terms of catalytic efficiency has been demonstrated by MWCNTs SPE-based biosensor. The inhibition biosensor shows a linearity range towards 2,4-D
\end{abstract}

Electronic supplementary material The online version of this article (doi:10.1007/s00216-016-9389-z) contains supplementary material, which is available to authorized users.

Franco Mazzei

franco.mazzei@uniroma1.it

1 Department of Chemistry and Drug Technologies, Sapienza University of Rome, Piazzale Aldo Moro 5, Rome 00185, Italy

2 Department of Chemistry, Sapienza University of Rome, Piazzale Aldo Moro 5, Rome 00185, Italy within 2.1-110 ppb, a LOD of $1 \mathrm{ppb}$, and acceptable repeatability and stability. This analysis method was applied to fortified lake water samples with recoveries above $90 \%$. The low cost of this device and its good analytical performances suggest its application for the screening and monitoring of 2,4-D in real matrices.

Keywords Screen printed electrode $\cdot$ Inhibition biosensor . Phosphatase alkaline $\cdot 2,4-\mathrm{D}$

\section{Introduction}

2,4-Dichlorophenoxy acetic acid (2,4-D) is an auxinic herbicide with grown regulator activity that has been widely used for controlling broadleaf weeds in cereal grain crops [1]. Because of its carcinogenic, teratogenic, and estrogenic activity, the presence of residues of 2,4-D in agricultural products and environment can be extremely harmful for both humans and animals [2, 3]. US Environmental Protection Agency (EPA) has set an enforceable regulation for 2,4-D, called a maximum contaminant level (MCL), at $0.07 \mathrm{mg} / \mathrm{L}$ or $70 \mathrm{ppb}$. Hence, a reliable and rapid technique for its determination is absolutely necessary to ensure both environmental and food safety.

In the course of the years, several analytical classic techniques such as high performance liquid chromatography (HPLC) [4], capillary electrophoresis [5], and gas chromatography (GC) [6] have been used for the determination of 2,4-D as well as for other environmental pollutants. These classic techniques give optimal results in terms of sensitivity, selectivity, and specificity but have also some drawbacks as they require expensive instrumentations, sample pretreatments, and well-trained staff. Moreover, they cannot be employed "in situ" for the monitoring in real time of these pollutants in 
the area of investigation. For these reasons, a new impulse towards the development of alternative analytical devices has been given in recent years in order to minimize the sample pretreatment, reduce the costs and time of analysis, and allow "in situ" determinations. Biosensors represent one of these alternatives and their application to environmental monitoring has been continuously growing in the last years $[7,8]$.

Several enzyme/antibody biosensors for the determination of 2,4-D have been developed, based on different transducers, such as electrochemical [9-17], surface plasmon resonance (SPR) [18-21], and optical [22, 23]. Unfortunately, also these sensors present some disadvantages such as poor chemical/ physical stability of the antibodies and enzymes which prevent their use. More recently, an electrochemical sensor based on the molecular imprinting technique has been reported [24] which showed promising results because of the high mechanical/chemical stability of the molecularly imprinted materials. Other biosensors for 2,4-D detection have been realized using whole cells as bioelements, such as Pseudomonas putida [25] and Anabaena torulosa [26]. Among the different biosensors employed in environmental analysis, a leading role is however represented by the inhibition-based biosensors [27-30].

Inhibition biosensors can be used for a double aim: (i) to study the kinetic characteristics of the inhibition process. In this case, the background theories and equations have to be modified to include the presence of heterogeneous phase. It has also to be taken in due account that most of the "biological responses" producing the biosensor signal refer to transient and/or local equilibria, and very seldom they can be traced to either Michaelis-Menten or the Briggs-Haldane models and (ii) to determine the concentration of the inhibitor in the assayed sample by measuring the percent of inhibition of the biocatalyst immobilized on the biosensor.

In the last 20 years many works described the realization of inhibition-based biosensors for the analysis of environmental pollutants [31-33]. In particular inhibition biosensors for pesticide and herbicide detection are all based on the inhibition of the catalytic activity of five enzymes: cholinesterase $(\mathrm{ChE})$ [34], tyrosinase (Tyr) [35], alkaline phosphatase (AlP) [36], peroxidase and acid phosphatase (AP) [33]. All biosensors reported in literature for 2,4-D detection are based on the inhibition of AlP. An inhibition biosensor for 2,4-D detection based on the activity of AlP combined with the activity of glucose oxidase [37] and successively another biosensor for the detection of 2,4-D and malathion by using only AlP enzyme and 3-indoxyl phosphate, phenyl phosphate or ascorbate-2-phosphate as enzyme substrates [38] have been recently realized in our laboratories. Other AlP-based biosensors for the 2,4-D detection were also described by Shyuan et al. [39] which realized a biosensor based on the entrapment of AlP in a hybrid sol-gel/chitosan film deposited on the surface of a screen printed electrode and by Loh et al. [40] which reported the use of $\mathrm{Fe}_{3} \mathrm{O}_{4}$ nanoparticles on a hybrid sol-gel/ chitosan membrane deposited on the top of a screen-printed carbon paste electrode for the enhancement of the response of an AlP-based biosensor.

In this work, we report the development and characterization of an alkaline phosphatase (AlP)-based biosensor for the determination of 2,4-D. The proposed biosensor is based on the inhibition effect of 2,4-D towards the catalytic activity of AlP. The enzyme was immobilized onto three different types of screen-printed electrodes: graphite $(\mathrm{G})$, graphene (GP), multiwalled carbon nanotubes (MWCNTs). Ascorbate 2phosphate was used as substrate to measure the catalytic activity of the enzyme.

Cyclic voltammetry and amperometry experiments were carried out to optimize the experimental conditions and to characterize the main bioelectrochemical properties of the biosensor. Several theoretical aspects involved in the firstgeneration inhibition-based electrochemical biosensor measurements have been discussed on the basis of the experimental data. Finally, the proposed biosensor was applied to the detection of 2,4-D in spiked lake water samples.

\section{Experimental}

\section{Materials}

The enzyme orthophosphoric-monoester phosphohydrolase (AlP, EC 3.1.3.1 from Bovine Liver, 3.4 U/mg solid), L-ascorbic acid 2-phosphate sesquimagnesium salt hydrate (A2P), 2 , 4-dichlorophenoxyacetic acid (2,4-D), Tris buffer, potassium chloride, magnesium chloride, $N$-(3-dimethylaminopropyl)$N^{\prime}$-ethylcarbodiimide hydrochloride (EDC), and $N$ hydroxysuccinimide (NHS) were purchased from SigmaAldrich (USA).

L-Ascorbic acid (AA) was purchased from Merck KGaA (Darmstadt, Germany). The polymeric film employed for the physicochemical enzyme immobilization was a photocrosslinkable poly(vinylalcohol) with styrylpyridinium groups (PVA-SbQ) obtained from Polysciences, Inc. (USA). All other chemicals used were analytical grade.

All measurements were carried out in $0.1 \mathrm{M}$ Tris buffer $\mathrm{pH}$ 9.5. All solutions have been prepared with high purity deionized water (Resistance: $18.2 \mathrm{M} \Omega \mathrm{xcm}$ at $25{ }^{\circ} \mathrm{C}$; TOC $<10 \mu \mathrm{g} \mathrm{L}^{-1}$ ) obtained from a system MilliQ-UV, Millipore (France).

\section{Biosensor preparation}

\section{AlP immobilization}

Method 1, PVA-SbQ: $4 \mathrm{mg}$ of AlP and $50 \mathrm{mg}$ of PVASbQ were solubilized in $400 \mu \mathrm{l}$ of distilled water. The 
resulting AlP-PVA-SbQ solution was homogenized by vortex-mixing and $4 \mu \mathrm{L}$ of this solution were spread on the working electrode. The final activity of AlP immobilized onto the electrode surface was about 0.14 U. The SPEs were successively exposed under a UV lamp $(\lambda=364 \mathrm{~nm})$ for $20 \mathrm{~min}$ at room temperature in order to allow the entrapment of the enzyme by photopolymerization.

Method 2, EDC-NHS: the carboxylic groups present on the surface of MWCNTs-SPE (previously oxidized with a drop of $\mathrm{HNO}_{3} 2 \mathrm{M}$ ) were activated with an aqueous solution of $0.5 \mathrm{M}$ EDC and $0.1 \mathrm{M}$ NHS for $20 \mathrm{~min}$. After removing EDC-NHS mixture by washing the electrode with deionized water and drying with $\mathrm{N}_{2}$ flow, $4 \mu \mathrm{L}$ of an aqueous solution of AlP $0.035 \mathrm{U} / \mu \mathrm{L}$ was spread onto the working electrode. After rinsing the surface of the MWCNTs working electrode with $0.1 \mathrm{M}$ Tris buffer pH 9.5, electrochemical measurements were carried out.

\section{Electrochemical measurements}

Amperometric experiments were performed by using a $\mu$ Autolab type III potentiostat (Eco Chemie, The Netherlands) controlled by the GPES Manager program (Eco Chemie, The Netherlands) with a conventional three electrodes configuration. Screen-printed working electrodes (DropSens, Oviedo, Spain) with a surface diameter of $4 \mathrm{~mm}$, formed by the following carbon materials, graphite $(\mathrm{G})$, graphene (GP), multi-walled carbon nanotubes (MWCNTs), were used. A silver/silver chloride electrode and a carbon electrode were used as reference and counter electrodes, respectively. Chronoamperometric and cyclic voltammetric experiments were carried out by using a thermostated cell (volume $5 \mathrm{~mL}$ ). The calibration plot was performed by adding several aliquots of ascorbate 2-phosphate standard solution at different concentrations into the buffer media $(0.1 \mathrm{M}$ Tris with $0.1 \mathrm{M} \mathrm{KCl} \mathrm{pH} \mathrm{9.5,} \mathrm{with} 0.1 \mathrm{M} \mathrm{MgCl}_{2}$ ). The linear and nonlinear regressions were calculated by using the software GraphPad Prism 5 from GraphPad Software Inc. (USA).

\section{Kinetic characterization}

To characterize the kinetic and the analytical data of the inhibitory effect of 2,4-D towards immobilized AIP, incubation procedure was carried out: in the first step, the biosensor was dipped into a buffer solution containing $1 \mathrm{mM}$ A2P by recording the current $\left(\mathrm{I}_{0}\right)$ at the fixed potential of $0.65 \mathrm{~V}$ vs. $\mathrm{Ag} / \mathrm{AgCl}$, then the same experiment has been repeated after an properly incubation time (see below) with known concentrations of herbicide standard solution, by recording the current value (I) every $120 \mathrm{~s}$ after each addition (Fig. 7).
Inhibition percentage was calculated as:

Inhibition percentage $=\frac{I_{0}-I}{I_{0}} \%$

\section{Preparation of water samples}

Real water samples were collected from three different sampling places in a lake from Lazio. In order to obtain several spiked samples, different aliquots of 2,4-D standard solution were added to the water samples to achieve a final herbicide concentration ranging from 25 to $100 \mathrm{ppb}$. All solutions were used without any pretreatment and were freshly prepared just before the measurements.

\section{Results}

A series of cyclic voltammetry experiments in the presence of $0.3 \mathrm{mM}$ AA in a $0.1 \mathrm{M}$ Tris buffer with $0.1 \mathrm{M} \mathrm{KCl} \mathrm{pH} 9.5$ at scan rate $10 \mathrm{mV} \mathrm{s}^{-1}$ were carried out to evaluate the best electrode material employing after in the AlP enzymatic catalysis. The anodic peak current arising from the electrochemical oxidation of AA was located at $0.65 \mathrm{~V}$ vs. $\mathrm{Ag} / \mathrm{AgCl}$ (Fig. 1). Differences in voltammetric signal of AA can be observed for every employed electrodic materials; the best performances in terms of highest limiting current were obtained by using MWCNTs SPE as electrochemical transducer.

An analogous experiment was performed with the MWCNTs modified electrodes with AlP immobilized into PVA-SbQ layer in the presence of $0.3 \mathrm{mM} \mathrm{A2P}$ and the AA produced by the enzymatic reaction was detected. The results obtained have been compared with the direct detection of the same concentrations of AA (Fig. 2).

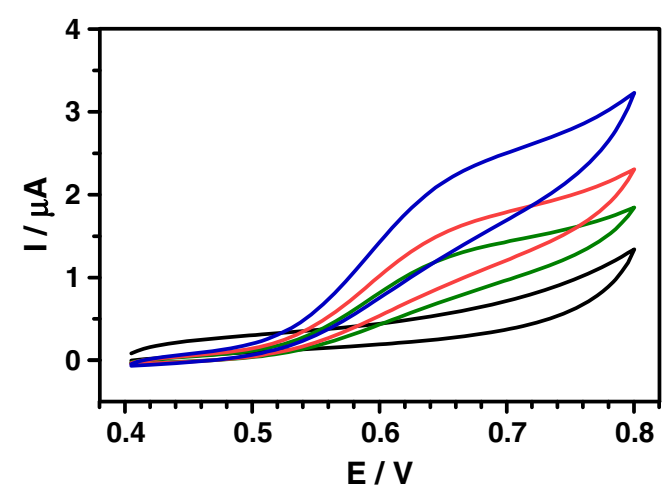

Fig. 1 Cyclic voltammetric experiments (vs. $\mathrm{Ag} / \mathrm{AgCl}$ ) performed in the presence of $0.3 \mathrm{mM}$ AA with MWCNTs/PVA-SbQ modified electrode (blank) (black line), G/PVA-SbQ modified electrode (green line); GP/ PVA-SbQ modified electrode (red line), MWCNTs/PVA-SbQ modified electrode (blue line). The electrochemical experiments were carried out in $0.1 \mathrm{M}$ Tris buffer with $0.1 \mathrm{M} \mathrm{KCl}, \mathrm{pH} 9.5$ at $37^{\circ} \mathrm{C}$ (scan rate $10 \mathrm{mV} / \mathrm{s}$ ) 


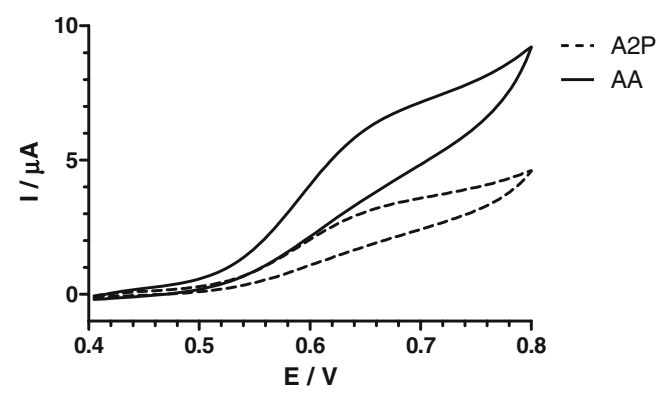

Fig. 2 Cyclic voltammetric experiments (vs. $\mathrm{Ag} / \mathrm{AgCl}$ ) of MWCNTs/ PVA-SbQ/AlP modified electrode performed in the presence of $0.3 \mathrm{mM}$ $\mathrm{A} 2 \mathrm{P}$ (dashed line) and $0.3 \mathrm{mM}$ AA (solid line). The electrochemical experiments were carried out in $0.1 \mathrm{M}$ Tris buffer with $0.1 \mathrm{M} \mathrm{KCl}$, pH 9.5 with $1 \mathrm{mM} \mathrm{MgCl} 2$ at $37^{\circ} \mathrm{C}$ (scan rate $10 \mathrm{mV} / \mathrm{s}$ )

\section{MWCNTs/PVA-SbQ/AIP biosensor characterization}

The characterization of the optimal experimental conditions ( $\mathrm{T}, \mathrm{pH}$, and $\mathrm{MgCl}_{2}$ concentration as cofactor) was realized and data are reported in the Electronic Supplementary Material (ESM) (see Figs. S2 to S4). The outcome of these measurements was as follows: $\mathrm{T} 37^{\circ} \mathrm{C}, \mathrm{pH} 9.5$, and $1 \mathrm{mM} \mathrm{MgCl}_{2}$.

The electroanalytical and kinetic properties of either MWCNTs, G or GP /PVA-SbQ/AlP biosensors were determined in a thermostated cell through amperometric experiments at a fixed potential of $0.65 \mathrm{~V}$ vs. $\mathrm{Ag} / \mathrm{AgCl}$, by adding known amounts of A2P standard solution in $0.1 \mathrm{M}$ Tris buffer with $0.1 \mathrm{M} \mathrm{KCl}, \mathrm{pH} 9.5$ at $37^{\circ} \mathrm{C}$ with $1 \mathrm{mM} \mathrm{MgCl}_{2}$ and by recording the amperometric signal every $120 \mathrm{~s}$ after each addition. An AA oxidation current increase produced by the AlP reaction was observed from these experiments, reaching a maximum value $\left(I_{\max }\right)$ corresponding to the saturation of all the active sites of the immobilized enzyme with a typical behavior of the Michaelis-Menten kinetic (Fig. 3).

The results obtained allowed us to calculate the main kinetic and electroanalytical parameters (Table 1); the apparent kinetic data were comparable with those reported in literature

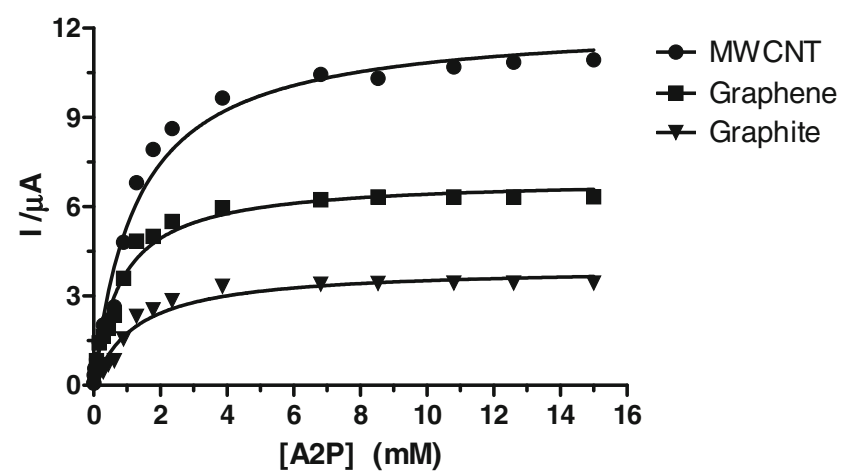

Fig. 3 Amperometric current response of MWCNTs, G, and GP/PVA$\mathrm{SbQ} / \mathrm{AlP}$ modified electrodes, with different concentrations of A2P standard solution. Experimental conditions: $0.1 \mathrm{M}$ Tris buffer with $0.1 \mathrm{M} \mathrm{KCl}$, pH 9.5 with $1 \mathrm{mM} \mathrm{MgCl} 2$ at $37{ }^{\circ} \mathrm{C}$, applied potential: $0.65 \mathrm{~V}$ vs. $\mathrm{Ag} / \mathrm{AgCl}$
[41], taking into account that different transducer materials affect calculated data.

In Fig. 4, a comparison of the amperometric current response of MWCNTs/PVA-SbQ/AlP and MWCNTs/EDCNHS/AlP modified electrodes, with different concentrations of A2P standard solution, was reported. As can be observed, the use of photopolymer PVA-SbQ as immobilizing agent coupled with MWCNTs as transducer allowed to improve the sensitivity of the resulting biosensor thanks to its thick layer hindering the diffusion of substrate [30, 42].

\section{Inhibition experiments}

The inhibition experiments were performed by incubating the AlP-based biosensor in the presence of 2,4-D known concentrations and then by evaluating the Michaelis Menten kinetic responses respect to those obtained in the absence of herbicide.

In Fig. 5, the results show the inhibition percentage of the MWCNTs/PVA-SbQ/AlP biosensor in the presence of 2,4-D at different incubation times. The inhibition process enhanced with incubation time increasing; in agreement on these results, we chose to perform our experiments for the determination of 2,4-D with an incubation time of $20 \mathrm{~min}$, which represented a good compromise between sensitivity and reduction of the analysis time.

The inhibition effect of 2,4-D has been evaluated by monitoring the amperometric current response of MWCNTs/PVA$\mathrm{SbQ} / \mathrm{AlP}$ modified electrode, with different concentrations of A2P standard solution in the presence of known amount of herbicide after 20 min of incubation time (Figs. 6 and 7).

\section{Inhibition kinetic characterization}

To recognize the inhibition mechanism of 2,4-D towards AlP, a set of Michaelis-Menten plots in the presence of 2,4-D different concentration were obtained (Fig. 8).

The kinetic parameters, $K_{M}^{I}$ and $I_{\max }^{I}$, were calculated at the different inhibitor concentrations. The obtained results were used to validate the inhibition mechanism by modelling experimental results using Prism 5.04 software from GraphPad Software, Inc. (USA), with respect to four different types of reversible inhibition: competitive, non-competitive, uncompetitive and mixed [43] (http://www.graphpad.com/guides/ prism/6/curve-fitting/index.htm?reg_mixered_model.htm).

In Table 2, the correlation coefficients obtained for the different types of inhibition are reported. The best fitting of the experimental data was obtained with the equation characteristic of the mixed inhibition and the calculated kinetic data were: $\alpha=2.76 ; \mathrm{K}_{\mathrm{I}}=29.62 \mathrm{ppb}$. Moreover, thanks to the reversibility of interaction, it was possible to reuse the amperometric biosensor for about 12 measurements with a $30 \%$ decreasing of its performance (see ESM Fig. S5). In Table 3, the main electroanalytical parameters of the MWCNTs/PVA- 
Table 1 Main kinetic and analytical parameters obtained with the several AlP biosensors, using $\mathrm{A} 2 \mathrm{P}$ as substrate

\begin{tabular}{lccccccc}
\hline Transducers & $\begin{array}{l}\text { Linearity } \\
\text { range }(\mu \mathrm{M})\end{array}$ & $\begin{array}{c}\mathrm{LOD}^{\mathrm{a}} \\
(\mu \mathrm{M})\end{array}$ & $\begin{array}{l}\text { Sensitivity } \\
\left(\mu \mathrm{AmM} \mathrm{mM}^{-1}\right)\end{array}$ & $I_{\max }(\mu \mathrm{A})$ & $\begin{array}{l}\mathrm{K}_{\mathrm{M}}{ }^{\text {app }} \\
(\mathrm{mM})\end{array}$ & $\begin{array}{l}I_{\max } / \mathrm{K}_{\mathrm{M}}{ }^{\mathrm{app}} \\
\left(\mu \mathrm{A} \mathrm{mM} \mathrm{mM}^{-1}\right)\end{array}$ & $\mathrm{r}$ \\
\hline MWCNTs & $17.0-890.1$ & 8.0 & $5.19 \pm 0.18$ & $12.22 \pm 0.36$ & $1.28 \pm 0.14$ & 9.5 & 0.9953 \\
Graphene & $80.2-890.1$ & 45.0 & $3.33 \pm 0.19$ & $6.94 \pm 0.19$ & $0.81 \pm 0.09$ & 8.6 & 0.9911 \\
Graphite & $\begin{array}{c}170.4- \\
890.1\end{array}$ & 82.0 & $1.49 \pm 0.05$ & $3.96 \pm 0.18$ & $1.27 \pm 0.21$ & 3.1 & 0.9963 \\
\hline
\end{tabular}

${ }^{\text {a }}$ LOD is calculated based on three times the standard deviation of the blank sample measurement
$\mathrm{SbQ} / \mathrm{AlP}$ biosensor in the analysis of 2,4-D standard solutions are reported.

\section{Theoretical considerations for AIP-based first generation electrochemical biosensors for 2,4-D detection}

We have developed, starting from previously published papers [44-49], a theoretical-methodological approach for the experimental characterization of the interaction between substrate and enzyme in presence of inhibitor thereof. According to the well-known enzymatic behavior, AlP is a hydrolase enzyme which is able to remove phosphate group from several substrates. In particular, in this work, we have taken into account the hydrolysis reaction of A2P to AA, according to Scheme 1 .

The catalytic activity is evaluated by amperometric monitoring the oxidation of the AA produced at the working electrode. According to the steady-state approach for solving the enzyme kinetic [50], the reaction rate catalyzed by AlP can be expressed by:

$v=\frac{k_{c a t}[A l P][A 2 P]}{K_{S}+[A 2 P]}$

In order to simplify the kinetic treatment of the electrochemically monitored AlP catalyzed reaction, the following boundary conditions have been arranged:

1. A2P and 2,4-D concentration at $\mathrm{x}=\mathrm{L}$ (where $\mathrm{L}$ is the Nernst layer thickness) is the same as that of the bulk solution (no mass transfer resistance of the liquid film).

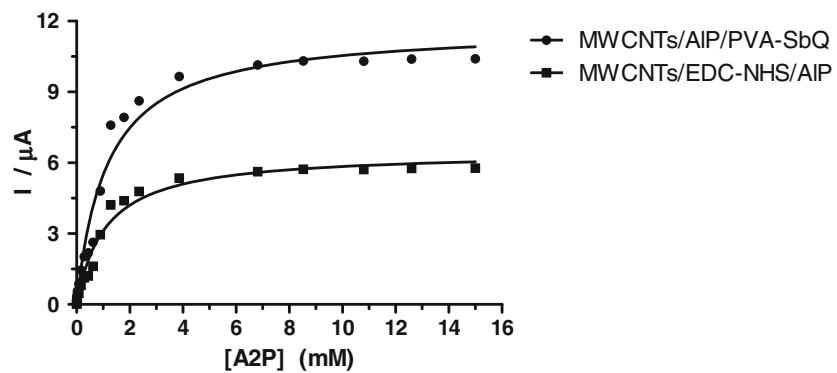

Fig. 4 Amperometric current response of MWCNT/PVA-SbQ/AlP and MWCNTs/EDC-NHS/AlP modified electrodes, with different concentrations of $\mathrm{A} 2 \mathrm{P}$ standard solution. Experimental conditions: $0.1 \mathrm{M}$ Tris buffer with $0.1 \mathrm{M} \mathrm{KCl}, \mathrm{pH} 9.5$ with $1 \mathrm{mM} \mathrm{MgCl}_{2}$ at $37{ }^{\circ} \mathrm{C}$, applied potential: $0.65 \mathrm{~V}$ vs. $\mathrm{Ag} / \mathrm{AgCl}$
2. AlP is homogeneously distributed throughout the PVASbQ layer.

3. The concentration of the oxidized form of the product AA on the electrode surface $(x=0)$ is equal to that one of the reduced form.

4. Diffusion occurs in only one dimension.

In the investigated system, we can observe the production of two kinds of flows: (i) scalar, having no direction in space; (ii) vectorial with directional properties.

The scalar flows are considered as derived from the hydrolysis of A2P to AA, and the interaction between 2,4-D and AlP, while the vectorial flows are due to diffusion phenomena of A2P and 2,4-D to the working electrode surface. Two different forces generate these flows: (i) affinity reactions, for scalar flows; (ii) chemical potential gradients, for diffusion flows.

Our experimental model considers A2P and AlP homogeneously distributed in the solution and in the immobilizing layer respectively. The mass conservation law is assumed as valid also when chemical and redox reactions take place (nonconservative case).

We can write:

$\frac{\partial c_{i}}{\partial t}=-\operatorname{div} J_{i}+v \frac{d \xi}{d t}$

Where $\mathrm{J}_{\mathrm{i}}$ is the flow, $v$ represents the stoichiometric coefficient, while $\frac{d \xi}{d t}$ is the rate of chemical change per unit volume.

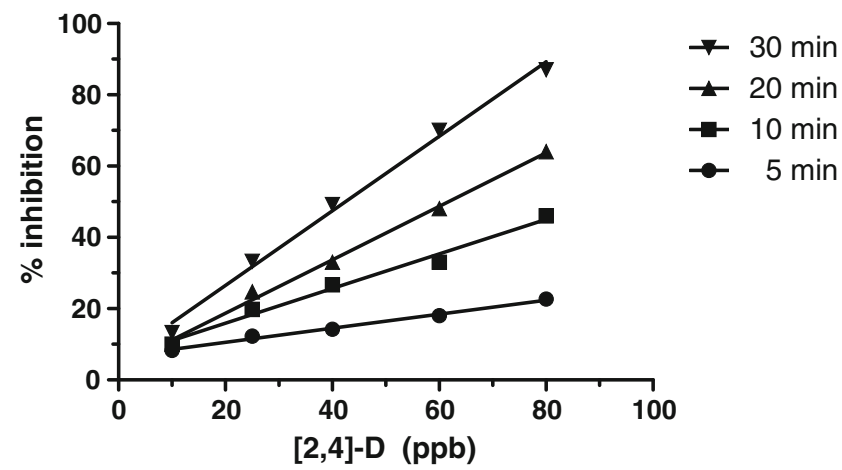

Fig. 5 Inhibition percentage of MWCNTs/PVA-SbQ/AlP biosensor in presence of known 2,4-D concentrations at different incubation times. Experimental conditions: $0.1 \mathrm{M}$ Tris buffer with $0.1 \mathrm{M} \mathrm{KCl}, \mathrm{pH} 9.5$ with $1 \mathrm{mM} \mathrm{MgCl}_{2}$ at $37^{\circ} \mathrm{C}$, applied potential: $0.65 \mathrm{~V} \mathrm{vs.} \mathrm{Ag} / \mathrm{AgCl}$ 


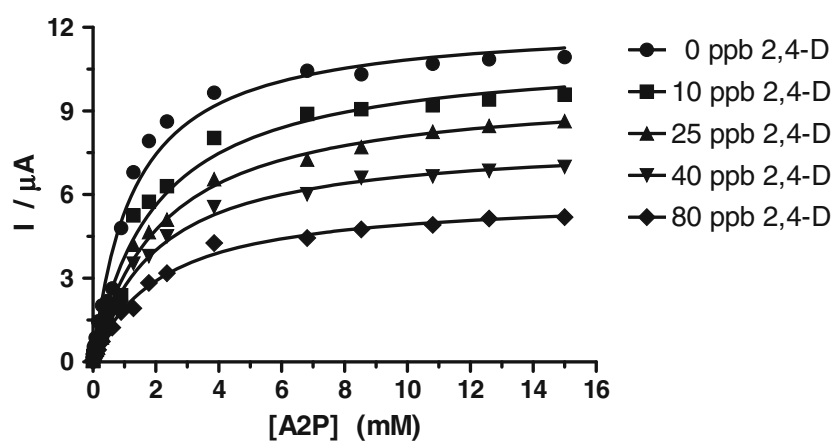

Fig. 6 Amperometric current response of MWCNTs/PVA-SbQ/AlP biosensor, for increasing $\mathrm{A} 2 \mathrm{P}$ concentration in presence of known herbicide concentrations at $20 \mathrm{~min}$ of incubation time. Experimental conditions: $0.1 \mathrm{M}$ Tris buffer with $0.1 \mathrm{M} \mathrm{KCl}, \mathrm{pH} 9.5$ with $1 \mathrm{mM}$ $\mathrm{MgCl}_{2}$ at $37^{\circ} \mathrm{C}$, applied potential: $0.65 \mathrm{~V}$ vs. $\mathrm{Ag} / \mathrm{AgCl}$

This can be further simplified into:

$\frac{\partial c_{i}}{\partial t}=-\operatorname{div} J_{i}+\sum v_{i}$

Where $v_{i}$ represents the rate reactions involving the substances taken into account.

Flow divergence $\left(\operatorname{div}\left(J_{i}\right)\right)$ can be expressed as:

$\operatorname{div}\left(J_{i}\right)=\frac{\partial J_{x}}{\partial x}+\frac{\partial J_{y}}{\partial y}+\frac{\partial J_{z}}{\partial z}$

By applying the first Fick's law in stationary state conditions: $J_{i}=-D \frac{d c_{i}}{d x}$, we can write:

$$
\begin{aligned}
& \operatorname{div}\left(J_{i}\right)=-D\left[\frac{\partial^{2} c}{\partial x^{2}}+\frac{\partial^{2} c}{\partial y^{2}}+\frac{\partial^{2} c}{\partial z^{2}}\right] \\
& \frac{\partial c}{\partial t}=\sum v_{i}+D\left[\frac{\partial^{2} c}{\partial x^{2}}+\frac{\partial^{2} c}{\partial y^{2}}+\frac{\partial^{2} c}{\partial z^{2}}\right]
\end{aligned}
$$

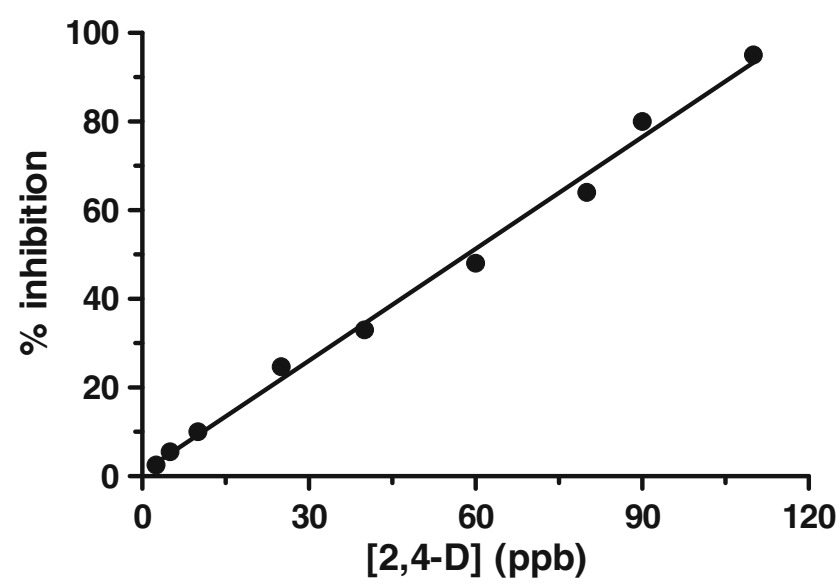

Fig. 7 Calibration graph \% inhibition vs. 2,4-D concentration in the presence of a fixed concentration of $\mathrm{A} 2 \mathrm{P}(1 \mathrm{mM})$ for an incubation time of $20 \mathrm{~min}$

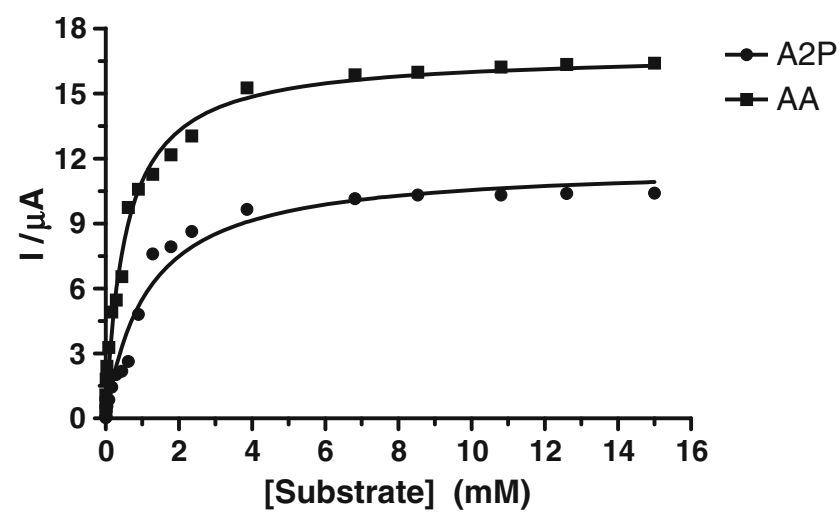

Fig. 8 Chronoamperometric experiments with the MWCNTs/PVA-SbQ/ AlP biosensor in the presence of A2P or AA. Experimental conditions: $0.1 \mathrm{M}$ Tris buffer with $0.1 \mathrm{M} \mathrm{KCl}$, pH 9.5 with $1 \mathrm{mM} \mathrm{MgCl}_{2}$ at $37{ }^{\circ} \mathrm{C}$, applied potential: $0.65 \mathrm{~V}$ vs. $\mathrm{Ag} / \mathrm{AgCl}$

By using a planar electrode, a monodimensional diffusion occurs:

$\frac{\partial c}{\partial t}=\sum v_{i}+D\left[\frac{\partial^{2} c}{\partial x^{2}}\right]$

By applying this equation to the AlP catalyzed reaction:

$\frac{\partial[A 2 P]}{\partial t}=D \frac{\partial^{2}[A 2 P]}{\partial x^{2}}-\frac{k_{c a t}^{a p p}[A l P]_{o}[A 2 P]}{[A 2 P]+K_{M}^{a p p}}$

Where $[A l P]_{o}$ is referred to the concentration in the PVASbQ immobilizing layer.

The resulting production of a current flow derives from the redox reaction of AA on the electrode surface.

Current intensity can thus be obtained by means of the following general equation:

$I=n D_{A 2 P} F A\left(\frac{\partial[A A]}{\partial x}\right)_{x=0}=n D_{A 2 P} F A \beta\left(\frac{\partial[A 2 P]}{\partial x}\right)_{x=0}$

where $\beta$ is the correction factor that takes into account the oxidation efficiency of AA in the presence and in the absence of AlP; $\beta$ value has been calculated as the current ratio between the two corresponding signals for a kinetic of zero order for the enzymatic reaction in order to evaluate the electrochemical response in the same conditions for the two substrates.

Table 2 Correlation coefficients referred to different inhibition models Inhibition type Correlation coefficients

$\begin{array}{ll}\text { Mixed } & 0.9946 \\ \text { Noncompetitive } & 0.9922 \\ \text { Uncompetitive } & 0.9839 \\ \text { Competitive } & 0.9859\end{array}$


Table 3 Main electroanalytical parameters obtained with the MWCNTs/PVA-SbQ/AlP biosensor in the analysis of 2,4-D standard solutions. Experimental conditions: $0.1 \mathrm{M}$ Tris buffer with $0.1 \mathrm{M} \mathrm{KCl}$, pH 9.5 with $1 \mathrm{mM} \mathrm{MgCl}_{2}$ at $37^{\circ} \mathrm{C}$, applied potential: $0.65 \mathrm{~V}$ vs. $\mathrm{Ag} / \mathrm{AgCl}$

Applied potential (V vs. $\mathrm{Ag} / \mathrm{AgCl})$

0.65

Linearity range (ppb)

$2.1-110.0$

Slope (inhibition \%/ppb)

0.84

Correlation coefficient

0.9940

Lower detection limit ${ }^{\mathrm{a}}(\mathrm{ppb})$

Reproducibility of the measurements (as pooled standard deviation in the linearity range) $(\%)$

${ }^{a}$ LOD is calculated based on three times the standard deviation of the blank sample measurement

The experimental determination of $\beta$ value has been realized by chronoamperometric measurements performed by two experiments with the MWCNTs/PVA-SbQ/AlP in the presence of A2P and AA (Fig. 8). According to the experimental data, $\beta$ value was calculated as $0.64 \pm 0.02$.

Considering the arranged experimental conditions, the solution of Eq. 9 leads to an equation indicating the attainment of a limiting current in stationary state conditions. The current changed as a function of A2P concentration and attained a limiting current value $\left(I_{\max }\right)$ when all the active sites of the immobilized AlP enzyme were saturated.

By applying this equation:

$I_{\lim }=\frac{I_{\max }[A 2 P]}{[A 2 P]+K_{M}^{a p p}}$

We have calculated the limiting current obtained in the presence of $0.3 \mathrm{mM} \mathrm{A} 2 \mathrm{P}$ and the result obtained is: $2.3 \pm 0.1 \mu \mathrm{A}$. The value is in good agreement with that one obtained as

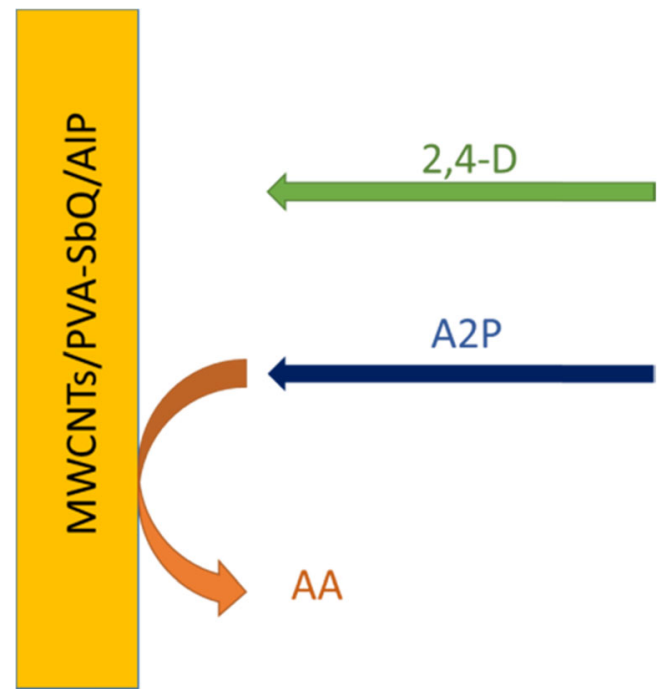

Scheme 1 Schematic representation of inhibition-based biosensor mechanism limiting current of cyclic voltammetry experiments (Fig. 1) with the MWCNTs/PVA-SbQ/AlP biosensor in the presence of the same concentration of A2P.

In the presence of the AlP inhibitor (2,4-D), according to the experimental data, indicating a mixed inhibition model for the interaction of AlP and inhibitor, the following equation can be applied:

$\frac{\partial[A 2 P]}{\partial t}=D_{S} \frac{\partial^{2}[A 2 P]}{\partial x^{2}}-\frac{I_{\max }^{I}[A 2 P]}{[A 2 P]+K_{M}^{I}}+D_{I} \frac{\partial^{2}[2,4-D]}{\partial x^{2}}$

Where $K_{M}^{I}$ is obtained according to the experimental data showing the mixed inhibition of AlP towards 2,4-D.

Moreover, the current recorded is:

$I_{\lim }=\frac{I_{\max }^{I}[A 2 P]}{[A 2 P]+K_{M}^{I}}$

\section{Real sample analysis}

Finally, the MWCNTs/PVA-SbQ/AIP biosensor was applied to the determination of the 2,4-D in four spiked samples of real water by using the standard addition method.

Aliquots of spiked samples were added to the electrochemical cell containing $5 \mathrm{~mL}$ of $0.1 \mathrm{M}$ Tris buffer with $0.1 \mathrm{M} \mathrm{KCl}$, pH 9.5 with $1 \mathrm{mM} \mathrm{MgCl}_{2}$ to obtain 2,4-D concentration of 25 , 50,75 and $100 \mathrm{ppb}$. For each sample, three determinations were performed, and the standard deviations were calculated (Table 4). As it can be observed, the found values are very close to the nominal ones, being the recovery always above $91 \%$ and accuracy (calculated as the percent ratio between measurement error and nominal value) between 0 and $8.3 \%$; these results are significantly better than those reported in literature by using similar inhibition systems for 2,4-D [35].

\section{Conclusions}

In this work, an inhibition AlP-based biosensor for 2,4-D determination was characterized both from the point of view of enzyme immobilization and that one of employed transducer.

Table 4 Experimental data obtained using MWCNTs/PVA-SbQ/AlP biosensor, in real water samples analysis (for each sample three determinations were carried out)

\begin{tabular}{llll}
\hline Nominal value (ppb) & Found value (ppb) & Recovery \% & Accuracy \% \\
\hline 25 & $23.1 \pm 0.4$ & 92.4 & -7.6 \\
50 & $50.0 \pm 0.9$ & 100 & 0 \\
75 & $74.2 \pm 1.5$ & 98.9 & -1.1 \\
100 & $91.7 \pm 1.8$ & 91.7 & -8.3 \\
\hline
\end{tabular}


Several theoretical aspects involved in the first-generation inhibition-based electrochemical biosensor measurements have been discussed. In particular, a theoretical-methodological approach for the kinetic characterization of the AlP/2,4-D interaction has been discussed.

As far as the detection of 2,4-D is concerned, under optimum experimental conditions, the best performance in terms of catalytic efficiency has been demonstrated by MWCNTs screen-printed electrode. The inhibition biosensor showed a linearity range towards 2,4-D within 2.1-110 ppb, a LOD of $1 \mathrm{ppb}$, and acceptable repeatability and stability. This analysis method was applied to spiked lake water samples with recoveries above $90 \%$.

This inhibition-based biosensor compared to other electrochemical biosensors for 2,4 D (commonly immunosensors) shows some peculiar advantages such as cheapness due to lower costs of enzyme versus antibody and higher reusability, since it can be used for 12 measurements with only a $30 \%$ decrease of its performance; no need to label the biorecognition element to perform the measurement.

The overall analytical performances suggest its application for the screening and monitoring of 2,4-D in real matrices.

Compliance with ethical standards This statement is to certify that all authors have neither conflict of interest to declare, nor research involving Human Participants and/or Animals.

\section{References}

1. Veldestra H. Plant hormones: synthetic auxin. Compr Biochem. 2014; 127-150.

2. Mostafalou S, Abdollahi M. Pesticides and human chronic diseases: evidences, mechanisms and perspectives. Toxicol Appl Pharmacol. 2013;268:157-77.

3. Garabrant DH, Philbert MA. Review of 2,4docholorophenoxyacetic acid (2,4-D) epidemiology and toxicology. Crit Rev Toxicol. 2002;32:233-57.

4. Wu JM, Ee KH, Lee HK. Automated dynamic liquid-liquid-liquid microextraction followed by high-performance liquid chromatography-ultraviolet detection for the determination of phenoxy acid herbicides in environmental waters. J Chromatogr A. $2005 ; 1082: 121-7$.

5. Zhu LY, Lee HK. Field-amplified sample injection combined with water removal by electroosmotic flow pump in acidic buffer for analysis of phenoxy acid herbicides by capillary electrophoresis. Anal Chem. 2001;73:3065-72.

6. Shin HS. Determination of phenoxy acid pesticides in frog and fish tissues by gas chromatography-mass spectrometry. Chromatographia. 2006;63:579-83.

7. Eggins B, editor. Biosensors: an introduction. Weinheim: WileyTeubner; 1996.

8. Cass AEG, editor. Biosensors: a practical approach. Oxford: Oxford University Press; 1990.

9. Kim GY, Shim J, Kang MS, Moon SH. Preparation of a highly sensitive enzyme electrode using gold nanoparticles for measurement of pesticides at the ppt level. J Environ Monit. 2008;10:632-7.

10. Deng AP, Yang H. A multichannel electrochemical detector coupled with an ELISA microtiter plate for the immunoassay of 2,4-dichlorophenoxyacetic acid. Sens Actuators B Chem. 2007;124:202-8.

11. Navratilova I, Skladal P. The immunosensors for measurement of 2, 4-dichlorophenoxyacetic acid based on electrochemical impedance spectroscopy. Bioelectrochemistry. 2004;62:11-8.

12. Bauer CG, Erementko AV, Ehrentreich-Forster E, Bier FF, Makower A, Halsall HB, et al. Zeptomole-detection biosensor for alkaline phosphatase in an electrochemical immunoassay for 2,4dichlorophenoxyacetic acid. Anal Chem. 1996;68:2453-8.

13. Medyantseva EP, Vertlib MG, Kutyreva MP, Khaldeeva EI, Budnikov GK, Eremin SA. The specific immunochemical detection of 2,4dichlorophenoxyacetic acid and 2,4,5trichlorophenoxyacetic acid pesticides by amperometric cholinesterase biosensors. Anal Chim Acta. 1997;347:71-8.

14. Kalab T, Skladal P. A disposable amperometric immunosensor for 2,4-dichlorophenoxy acetic acid. Anal Chim Acta. 1995;304:361-8.

15. Dzantiev BB, Zherdev AV, Yulaev MF, Sitdikov RA, Dmitrieva NM, Yu Moreva I. Electrochemical immunosensors for determination of the pesticides 2,4-dichlorophenoxyacetic and 2,4,5-tricholorophenoxyacetic acids. Biosens Bioelectron. 1996;11:179-85.

16. Trau D, Theuerl T, Wilmer M, Meusel M, Spener F. Development of an amperometric flow injection immunoanalysis system for the determination of the herbicide 2,4-dichlorophenoxyacetic acid in water. Biosens Bioelectron. 1997;12:499-510.

17. Dequaire M, Degrand C, Limoges B. An immunomagnetic electrochemical sensor based on a perfluorosulfonate-coated screenprinted electrode for the determination of 2,4dichlorophenoxyacetic acid. Anal Chem. 1999;71:2571-7.

18. Gobi KV, Kim SJ, Tanaka H, Shoyama Y, Miura N. Novel surface plasmon resonance (SPR) immunosensor based on monomolecular layer of physically-adsorbed ovalbumin conjugate for detection of 2,4-dichlorophenoxyacetic acid and atomic force microscopy study. Sens Actuators B Chem. 2007;123:583-93.

19. Kim SJ, Gobi KV, Tanaka H, Shoyama Y, Miura N. A simple and versatile self-assembled monolayer based surface plasmon resonance immunosensor for highly sensitive detection of 2,4-D from natural water resources. Sens Actuators B Chem. 2008;130:281-9.

20. Gobi KV, Tanaka H, Shoyama Y, Miura N. Highly sensitive regenerable immunosensor for label-free detection of 2,4dichlorophenoxyacetic acid at ppb levels by using surface plasmon resonance imaging. Sens Actuators B Chem. 2005;111:562-71.

21. Kim SJ, Gobi KV, Iwasaka H, Tanaka H, Miura N. Novel miniature SPR immunosensor equipped with all-in-one multichannel sensor chip for detecting low-molecular-weight analytes. Biosens Bioelectron. 2007;23:701-7.

22. Mosiello L, Nencini L, Segre L, Spanò M. A fibre-optic immunosensor for 2,4-dichlorophenoxyacetic acid detection. Sens Actuators B Chem. 1997;39:353-9.

23. Long F, Shi HC, He M, Zhu AN. Sensitive and rapid detection of 2,4-dichlorophenoxyacetic acid in water samples by using evanescent wave all-fiber immunosensor. Biosens Bioelectron. 2008;23:1361-6.

24. Xie C, Gao S, Guo Q, Xu K. Electrochemical sensor for 2,4dichlorophenoxy acetic acid using molecularly imprinted polypyrrole membrane as recognition element. Microchim Acta. 2010;169: 145-52.

25. Odaci D, Sezginturk MK, Timur S, Pazarlioglu N, Pilloton R, Dinckaya E, et al. Pseudomonas putida based amperometric biosensors for 2-4-D detection. Prep Biochem Biotechnol. 2009;39: $11-9$.

26. Wong LS, Lee YH, Surif S. Whole cell biosensor using Anabaena torulosa with optical transduction for environmental toxicity evaluation. J Sens. 2013; 1-8. 
27. Kramer PM. Biosensors for measuring pesticides residues in the environment: past, present and future. J Assoc Off Anal Chem Int. 1996;79:1245-54

28. Botrè C, Botrè F, Lorenti G, Mazzei F, Porcelli F, Scibona G, et al. Cholinesterase based bioreactor for determination of pesticides. Sens Actuators B. 1994;19:689-93.

29. Mazzei F, Botrè F, Lorenti G, Porcelli F, Scibona G, Simonetti G, et al. Plant tissue electrode for the determination of atrazine. Anal Chim Acta. 1995;316:79-82.

30. Mazzei F, Botrè F, Botrè C. Acid phosphatase/glucose oxidasebased biosensors for the determination of pesticides. Anal Chim Acta. 1996;336:67-75.

31. Amine A, Mohammadi H, Bourais I, Palleschi G. Enzyme inhibition-based biosensors for food safety and environmental monitoring. Biosens Bioelectron. 2006;21:1405-23.

32. Bachan Upadhyay LS, Verma N. Enzyme inhibition based biosensors: a review. Anal Lett. 2013;46:225-41.

33. Sassolas A, Prieto-Simón B, Marty J-L. Biosensors for pesticide detection: new trends. Am J Anal Chem. 2012;3:210-32.

34. Arduini F, Amine A, Moscone D, Palleschi G. Biosensors based on cholinesterase inhibition for insecticides, nerve agents and aflatoxin B1 detection (review). Microchim Acta. 2010;170:193-214.

35. Vidal JC, Bonel L, Castillo JR. A modulated tyrosinase enzymebased biosensor for application to the detection of dichlorvos and atrazine pesticides. Electroanalysis. 2008;20:865-73.

36. Garcia Sanchez F, Navas Diaz A, Ramos Peinado MC, Belledone C. Free ans sol-gel immobilized alkaline phosphatase-based biosensor for the determination of pesticides and inorganic compounds. Anal Chim Acta. 2003;484:45-51.

37. Botrè C, Botrè F, Mazzei F, Podestà E. Inhibition-based biosensors for the detection of environmental contaminants: determination of 2,4dichlorophenoxyacetic acid. Environ Toxicol Chem. 2000;19:2876-81.

38. Mazzei F, Botrè F, Montilla S, Pilloton R, Podestà E, Botrè C. Alkaline phosphatase inhibition based electrochemical sensors for the detection of pesticides. J Electroanal Chem. 2004;574:95-100.

39. Shyuan LK, Heng LY, Ahmad M, Aziz SA, Ishak Z. Evaluation of pesticide and heavy metal toxicity using immobilized enzyme alkaline phosphatase with an electrochemical biosensor. Asian J Biochem. 2008;3:359-65.

40. Loh K-S, Lee YH, Musa A, Salmah AA, Zamri I. Use of $\mathrm{Fe}_{3} \mathrm{O}_{4}$ nanoparticles for enhancement of biosensor response to herbicide 2 , 4-dichlorophenoxyacetic acid. Sensors. 2008;8:5775-91.

41. Carralero SV, Luz MM, González-Cortés A, Yáñez-Sedeño P, Pingarrón JM. Development of a tyrosinase biosensor based on gold nanoparticles-modified glassy carbon electrodes: application to the measurement of a bioelectrochemical polyphenols index in wines. Anal Chim Acta. 2005;528(1-3):1-8.

42. Di Fusco M, Favero G, Mazzei F. Polyazetidine-coated microelectrodes: electrochemical and diffusion characterization of different redox substrates. J Phys Chem B. 2011;115:972-9.

43. Copeland RA. Evaluation of enzyme inhibitors in drug discovery. Wiley 2005 IBSN:0471686964

44. Dequaire M, Limoges B, Moiroux J, Savéant J-M. Mediated electrochemistry of horseradish peroxidase. Catalysis and inhibition. J Am Chem Soc. 2002;124(2):240-53.

45. Bourdillon C, Demaille C, Moiroux J, Savéant J-M. New insights into the enzymic catalysis of the oxidation of glucose by native and recombinant glucose oxidase mediated by electrochemically generated one-electron redox cosubstrates. J Am Chem Soc. 1993;115(1):1-10.

46. Savéant J-M, editor. Elements of molecular and biomolecular electrochemistry: an electrochemical approach to electron transfer chemistry. New York: Wiley; 2006.

47. Kano K, Ikeda T. Fundamentals and practices of mediated bioelectrocatalysis. Anal Sci. 2000;16:1013-21.

48. Kano K, Ohgaru T, Nakase H, Ikeda T. Electrochemical evaluation of redox enzyme reaction kinetics based on mediated bioelectrocatalysis in solution. Chem Lett. 1996;6:439-40.

49. Bartlett PN, Toh C-S, editors. Biosensors: a practical approach. Oxford: Oxford University Press; 2004.

50. Baronas R, Ivanauskas F, Kulys J. Mathematical modeling of biosensors: an introduction for chemists and mathematicians. Netherlands: Springer; 2010. 